\title{
Image Correction for Quantitatively Determining Harvest Time of Apple Outdoors
}

\author{
Masaki ISHII* and Ikumi KUSADA** \\ ${ }^{*}$ Department of Electronics and information Systems, Faculty of Systems Science and Technology, \\ Akita Prefectural University, 84-4, Aza Ebinokuchi Tsuchiya, Yurihonjo 015-0055, Japan \\ ${ }^{* *}$ Course of Machine and Intelligence Systems, Graduate School of Systems Science and Technology, \\ Akita Prefectural University, v84-4, Aza Ebinokuchi Tsuchiya, Yurihonjo 015-0055, Japan \\ E-mail: ishii@akita-pu.ac.jp
}

\begin{abstract}
The proper time to harvest high-quality fruits is determined by comparing fruits from different trees with reference to a color chart for each variety. This standard of assessment is not unified because it is based on appearances. Machines that have been developed to determine the proper time to harvest fruits are ineffective as they tend to misclassify unripe fruits as ripe. Thus, in this paper, we aim to develop a system that can accurately determine the proper time to harvest apples from a given tree. In previous studies, we had conducted an indoor experiment to determine the proper time to harvest apples. This had revealed that the $\mathrm{H}$ in the HSV color space and the $\mathrm{a}^{*}$ in the $\mathrm{L}^{*} \mathrm{a}^{*} \mathrm{~b}^{*}$ color space are useful in determining the appropriate time. However, outdoor lighting conditions change according to time and weather; therefore, we introduce an image correction method to reduce the influence of lighting conditions.
\end{abstract}

Keywords : Image processing, Determination of appropriate harvest time, Sensory inspection

\section{INTRODUCTION}

In recent years, the circumstances and environment related to agricultural and rural areas in Japan have been changing drastically because of economic globalization, falling birthrates, and an aging population. There has been a decline in agricultural revenue because of sluggish prices of crops, aging workers, increasing number of abandoned cultivable land, and so on. This has led to greater unease and uncertainty regarding the future of agricultural management. Figure 1 shows Farmer population and average age in Japan. In this Figure, the agricultural workforce, which was $2,98,5000$ in 2008, decreased to 2,097,000 in 2015. Moreover, the average age of employed people declined from 64.7 years to 66.4 years from 2008 to 2015 , and this aging of the workforce is steadily progressing ${ }^{[1]}$. The decrease in the numbers of agricultural workers

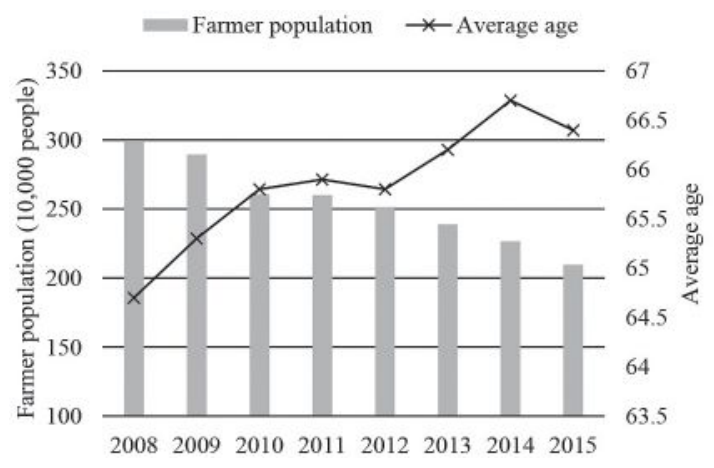

Figure 1 Farmer population and average age in $\operatorname{Japan}^{[1]}$. and their aging is a major problem for the future of Japanese agriculture.

In this backdrop, collaboration between agriculture and industry, with the aim of applying state-of-the-art engineering technologies to agriculture, is increasing ${ }^{[2][3][4][5][6]}$. Crop cultivation and management have been carried out using Information Technology, such as in the case of fully controlled plant factories, and robotics has been used with the aim of reducing the workload of farmers. These are instances of agri- innovation. Agriculture-industry collaboration is indispensable for the future health and sustainable development of agriculture.

Apples are widely cultivated in the Yokote Hiraka district of the Akita prefecture inland. Therefore, a method that can ensure the harvest of high-quality agricultural crops without relying on experience or intuition would be useful. According to the harvest season, the varieties of apple are classified into three typesearly, middle, and late varieties — and harvesting methods can be divided into two kinds. The first involves collecting and harvesting apples that have reached maturity, and is used in late varieties, such as Fuji. The second method involves harvesting apples while determining the degree of maturity of each apple, and is mainly used for high-quality early and middle varieties. In the latter harvesting method, a color chart is used as index to determine the time to harvest. An example of the use of the color chart is shown in Figure 2. The worker compares the color from the chart with those of the surfaces of the apples and the ground to determine whether it should be harvested. However, because this examination is based on sense information, it is subjective, and hence the standards of determination cannot be unified at present.

Many inspection apparatuses that can automatically classify 


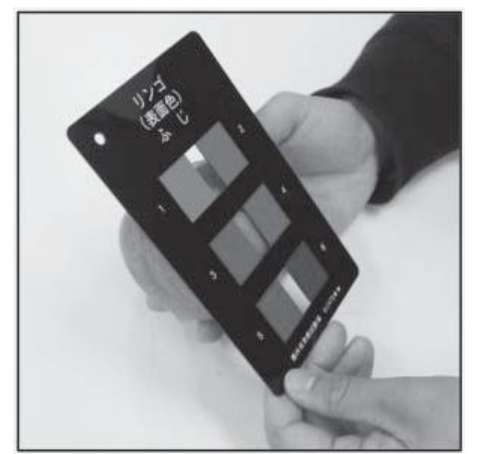

Figure 2 An example of using the color chart for surface color of apple.

apples have been developed in research. However, most of them are applied to apples after they are harvested, which is inefficient because the apples to be examined then include a number of immature ones as well. Therefore, we believe that if only ripe apples can be harvested without picking off immature ones, this can contribute to efficient agricultural management.

In this study, we aim to support the production of high-quality agricultural crops by developing a system to determine the quality of apples on trees at the time of harvest. The previous studies focused on the HSV (representing, hue, saturation, value) and $\mathrm{L} * \mathrm{a} \mathrm{b}^{*}$ (representing, lightness, green-red, blue-yellow) color spaces and found the $\mathrm{H}$ and $\mathrm{a}^{*}$ values are useful to determine the proper harvest time ${ }^{[7]}$. However, acquiring accurate apple color information is difficult because lighting conditions change according to time and weather. Thus, directly applying this method, which is an indoor method, is difficult. Therefore, we proposed an image correction method to reduce the influence of lighting conditions ${ }^{[8]}$. In this paper, we show the results of experiments on outdoor harvesting determination and verify the usefulness of the image correction method.

\section{COLOR SPACE TO DETERMINE PROPER TIME TO HARVEST}

We examined the color space used to determine the time to harvest apple outdoor. We focus on the (u, v) chromaticity diagram with uniform color difference, in addition to the HSV and $\mathrm{L}^{*} \mathrm{a} * \mathrm{~b} *$ color spaces $^{[9][10][11]}$.

There are two kind of color charts of apple (Fuji): one for surface color and one for ground color; the surface color is decided in 6 stages, and the ground color is done in 8 stages. First, a color chart (ground color) was analyzed indoors using a colorimeter (x-rite Co., ilpro). The results are shown in Figure 3. According to Figure $3, \mathrm{H}$ decreased with increasing chart number, and $\mathrm{a}^{*}$ and $\mathrm{u}$ tended to increase. The color charts were then captured outdoors using a digital camera (Sony, NEX-3D) and analyzed. The results are shown in Figure 4. It shows that the colorimeter obtained the same results in the outdoor environment for the values of $\mathrm{H}, \mathrm{a}^{*}$, and $\mathrm{u}$, and the coefficient of determination also assumed a high value. From the above, we conclude that $\mathrm{H}, \mathrm{a}^{*}$, and $\mathrm{u}$ are useful to determine the proper time to harvest outdoor.

\section{PROPOSED METHOD}

\subsection{Overview}

Changes in outdoor lighting conditions depend on the weather and time of day. Therefore, in this paper, we propose an image processing method to reduce the influence of the change in outdoor lighting on the determination of the time to harvest apple. The proposed method involves a color chart for correction (ColorChecker Passport, X-Rite) together with the given apple. The color chart used black, white, and gray for correction. This

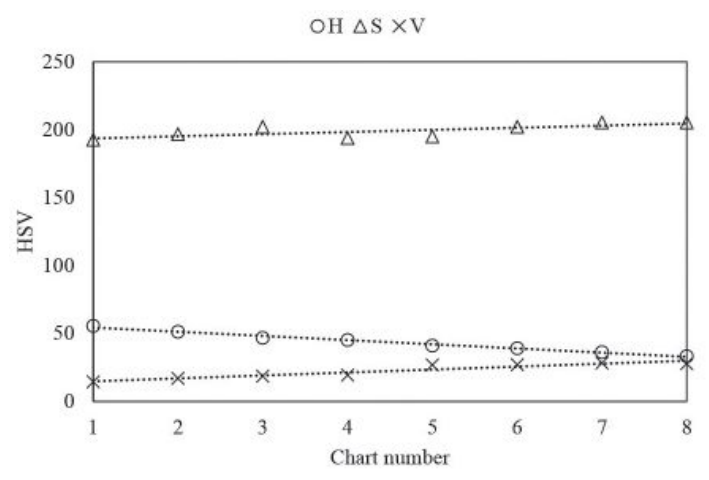

(a) Result of color chart analysis (HSV)

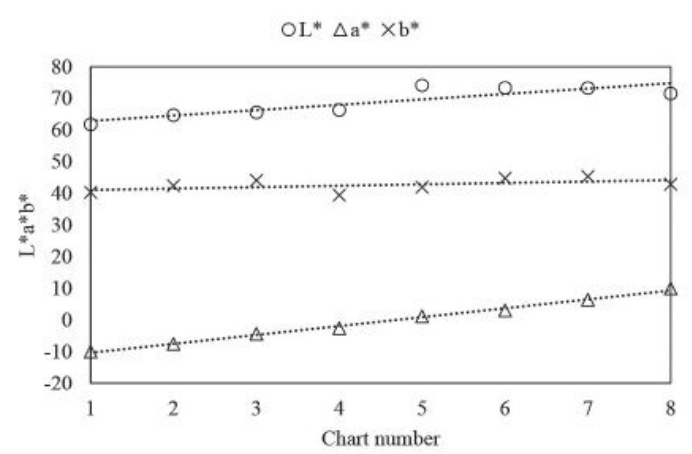

(b) Result of color chart analysis $\left(\mathrm{L}^{*} \mathrm{a} * \mathrm{~b} *\right)$.

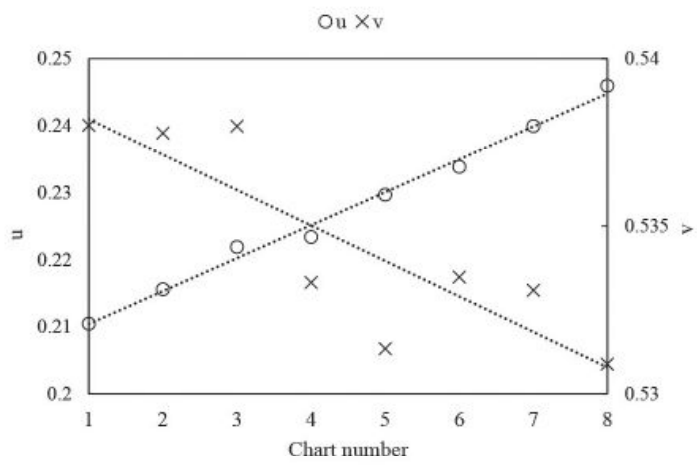

(c) Result of color chart analysis (u, v).

Figure 3 Results of color chart analysis.

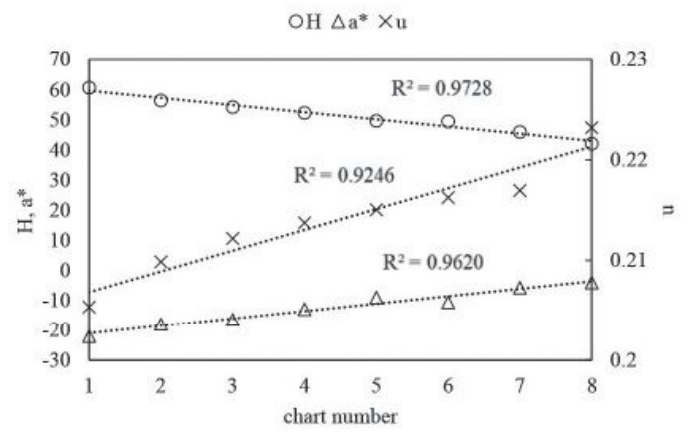

Figure 4 Results of color chart analysis (outdoor) 
constitutes contrast and gamma corrections. The correction was performed as follows: halation removal, contrast correction, and gamma correction.

\subsection{Contrast correction}

Contrast correction is performed on a raw image using the pixel values of the white and black charts. The correction is calculated as follows:

$$
R_{x, y}^{\prime}=255 \times \frac{R_{x, y}-B p_{R}}{W p_{R}-B p_{R}}
$$

where, $R_{x, y}, R_{x, y}^{\prime}$ are the $\mathrm{R}$ in $\mathrm{RGB}$ values in the corrected and the raw images, respectively, and $W p_{R}$ and $B p_{R}$ are $\mathrm{R}$ values acquired from the white and black charts, respectively. The same correction is also applied to $\mathrm{G}$ and $\mathrm{B}$. The results of contrast correction are shown in Figure 5(b).

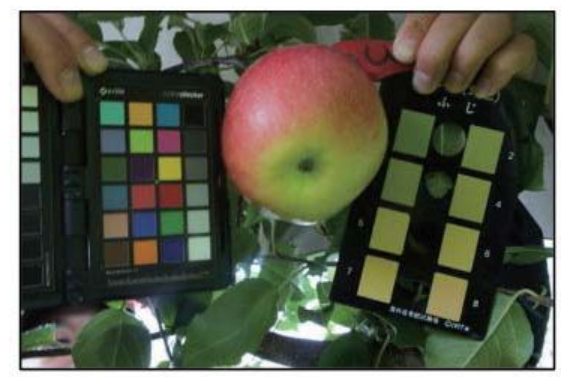

(a) Raw image.

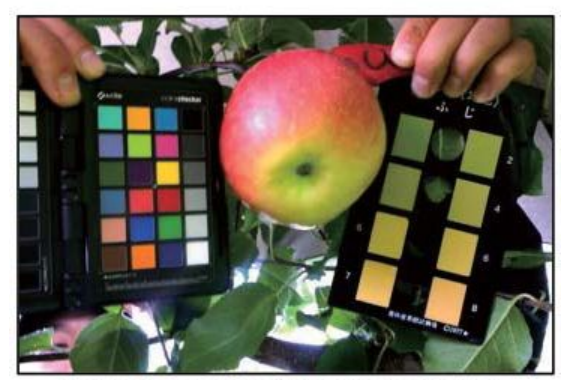

(b) Image obtained after contrast correction.

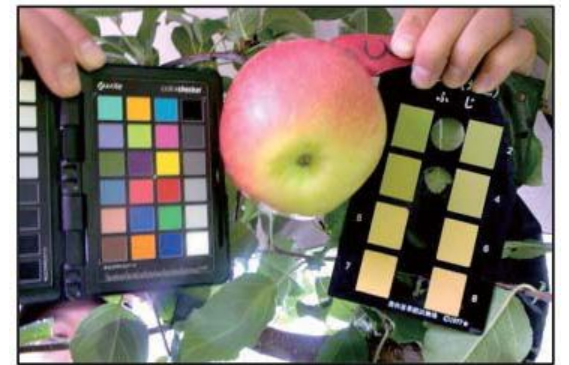

(c) Image obtained after gamma correction.

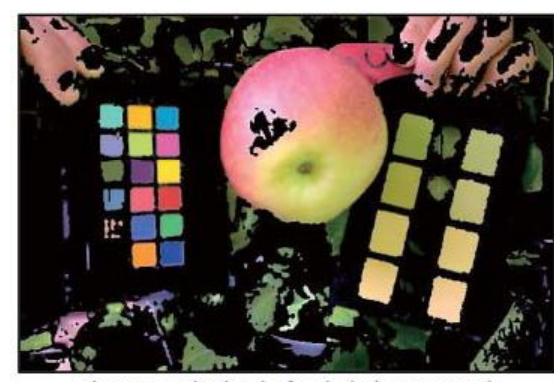

(d) Image obtained after halation removal.

Figure 5 Result of each processing step of the proposed method.

\subsection{Gamma correction}

Gamma correction is performed on the image following contrast correction using the pixel values of the gray chart (reflectance: $18 \%)$. This correction is calculated as follows:

$$
\begin{gathered}
R_{x, y}^{\prime \prime}=255 \times\left(\frac{R_{x, y}}{255}\right)^{r_{R}} \\
\left(\text { Gray }_{R}\right)^{r}=119
\end{gathered}
$$

where $\mathrm{Gray}_{R}$ is the $\mathrm{R}$ value acquired from the gray chart. The same correction is applied to $\mathrm{G}$ and $\mathrm{B}$. The results of contrast correction are shown Figure 5(c).

\subsection{Halation correction}

Halation can feature as white color in parts of the image due to overexposure. Color information cannot be accurately acquired with halation in the image. Therefore, the standard deviation of the RGB value in each pixel is calculated as in Eq. (3). Moreover, pixels with values lower than the threshold are removed as halation:

$\sigma=\sqrt{\left.\frac{1}{3}\left\{\left(R_{n}-A v g_{R G B}\right)^{2}+\left(G_{n}-A v g_{R G B}\right)^{2}+\left(B_{n}-A v g_{R G B}\right)^{2}\right\}\right)}$

where $R_{n}, G_{n}$, and $B_{n}$ are the RGB values of each pixel and $A v g_{R G B}$ is the average value of RGB in each pixel. The results of contrast correction are shown in Figure 5(d).

\section{VERIFICATION OF THE PROPOSED METHOD}

\subsection{Object of analysis}

We used apples and the color chart outdoor, and analyzed them using the proposed method. We used 12 apples (Yataka) cultivated in the Akita Prefecture Fruit Experiment Station. These apples were used with the color chart for correction and to determine the apple color using a digital camera (NEX-3D, Sony). The photography was carried out at roughly one-week intervals until the apples were ripe for harvest. The harvested apples were photographed together with the color charts indoor. An image from this stage is shown in Figure 6.

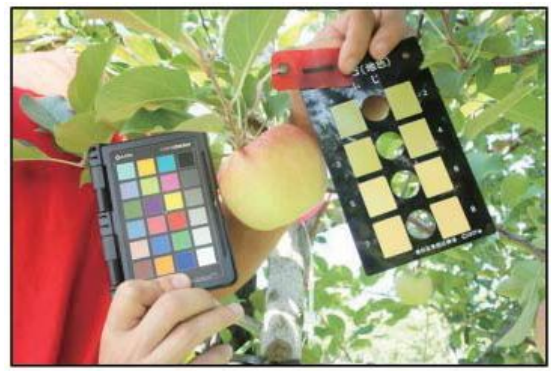

(a) Outdoor image.

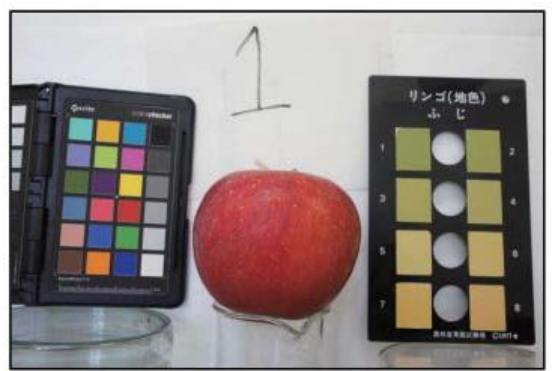

(b) Indoor image.

Figure 6 Object of analysis 


\subsection{Analysis of color chart}

We verified whether the proposed method was useful. The color chart was used to analyze the materials using the ground color of the apple. Figures 7 and 8 show the result with a focus on $\mathrm{a}^{*}, \mathrm{H}$ and $\mathrm{u}$, respectively. The images therein were captured at different dates and times. However, the color chart value in the correction image was supposed to be the same regardless of the date. The $\mathrm{H}, \mathrm{a}^{*}$, and $\mathrm{u}$ values in Figure 7 significantly varied because of differences in

Table 1 The standard deviation of color charts of all images.

\begin{tabular}{c|cc|cc|cc}
\hline \multirow{2}{*}{ Chart No. } & \multicolumn{2}{|c|}{$\mathrm{H}$} & \multicolumn{2}{c|}{$\mathrm{a}^{*}$} & \multicolumn{2}{c}{$\mathrm{u}(\times 100)$} \\
\cline { 2 - 7 } & Raw & Corrected & Raw & Corrected & Raw & Corrected \\
\hline 1 & 6.988 & 4.259 & 5.920 & 4.593 & 0.649 & 0.383 \\
2 & 6.574 & 4.107 & 5.624 & 4.414 & 0.589 & 0.379 \\
3 & 6.142 & 3.188 & 5.313 & 3.571 & 0.514 & 0.314 \\
4 & 7.464 & 2.974 & 5.437 & 3.232 & 0.519 & 0.316 \\
5 & 6.014 & 2.786 & 5.224 & 2.737 & 0.450 & 0.268 \\
6 & 5.929 & 2.768 & 5.145 & 2.670 & 0.469 & 0.355 \\
7 & 5.518 & 2.990 & 4.953 & 2.559 & 0.565 & 0.482 \\
8 & 5.661 & 3.326 & 4.738 & 2.776 & 0.556 & 0.649 \\
\hline
\end{tabular}

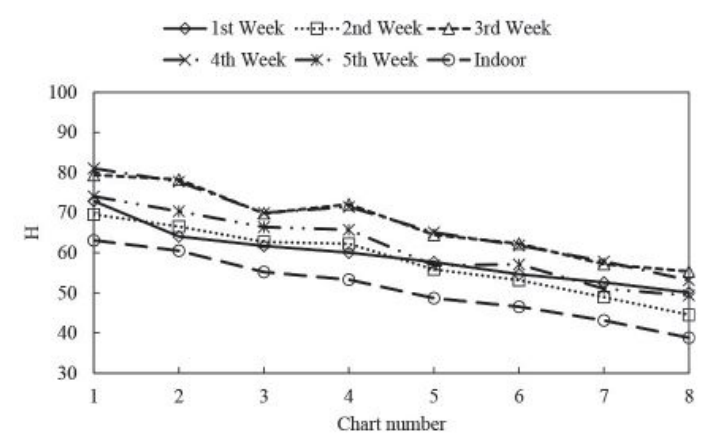

(a) $\mathrm{H}$

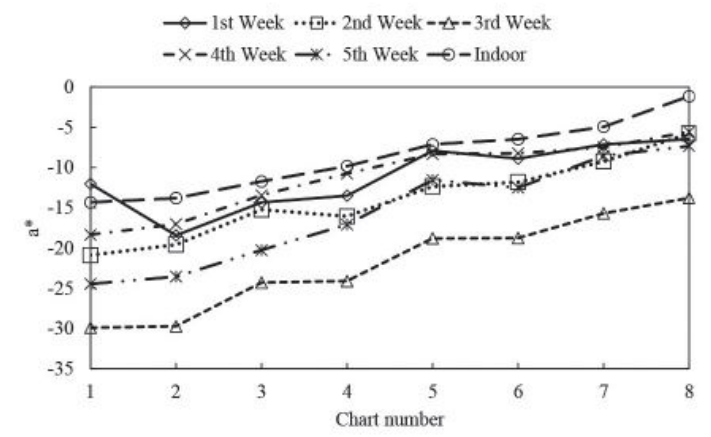

(b) $a^{*}$

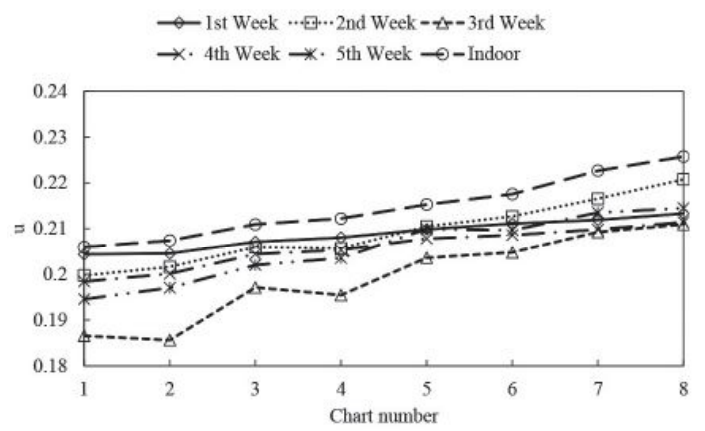

(c) $\mathrm{u}$

Figure 7 Result of apple color chart analysis (raw) the recording date. The corrected image values in Figure 8 roughly matched. Table 1 shows the standard deviation of the values of each chart number in all captured images. The table shows that the standard deviation of the color chart in the corrected image was sufficiently small. This result suggests that the proposed method is useful in reducing the influence of changing lighting conditions.

\subsection{Analysis of apple color}

We also analyzed the ground color of the apple to verify the proposed method. The halation threshold was set to 35 , and the analysis area was set manually. Figure 9 shows the color variation of the surface of the apple and the ground in sample No. 6. We have confirmed the improvement by the correction method in all 12 samples. Sample No. 6 is one the most significant improvement was observed. The Figure also shows that $\mathrm{a}^{*}$ and $\mathrm{u}$ increased in value and $\mathrm{H}$ decreased over time. Therefore, variations were found in the values of $\mathrm{H}, \mathrm{a}^{*}$, and $\mathrm{u}$ in the raw image. However, values along the state of growth were observed in the corrected image. Moreover, the coefficient of determination of the fitting curve of the corrected image was higher than that of the raw image.

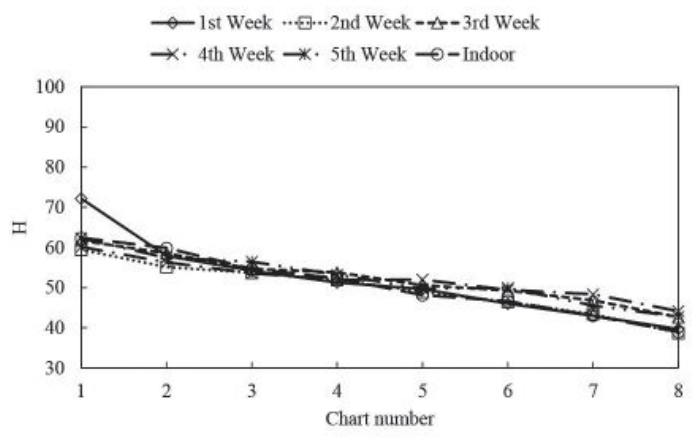

(a) $\mathrm{H}$

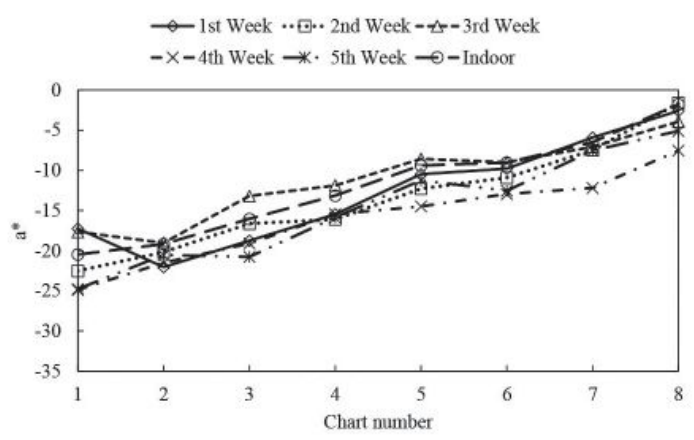

(b) $\mathrm{a}^{*}$

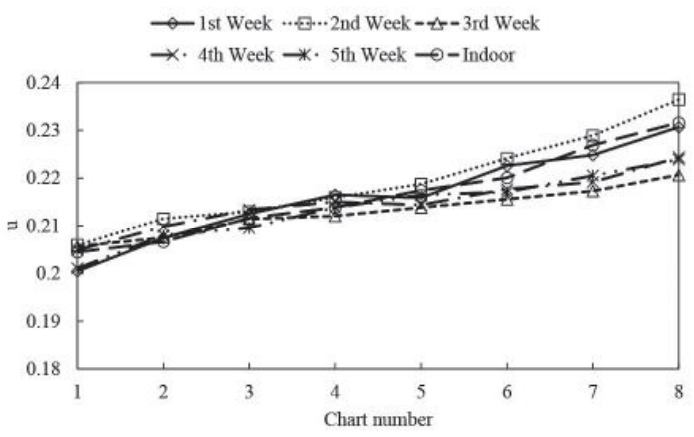

(c) $\mathrm{u}$

Figure 8 Result of apple color chart analysis (corrected) 
Table 2 Results of proposed method using 3D Euclidean distance.

\begin{tabular}{|c|c|c|c|c|c|c|c|c|c|}
\hline \multirow{2}{*}{$\begin{array}{c}\text { Sample } \\
\text { No. }\end{array}$} & \multirow{2}{*}{$\begin{array}{l}\text { Expert visual } \\
\text { judgments }\end{array}$} & \multicolumn{2}{|c|}{$\begin{array}{l}\text { Determination results of } \\
\text { proposed method }\end{array}$} & \multicolumn{2}{|c|}{$\begin{array}{l}\text { Difference from expert visual } \\
\text { judgments (absolute value) }\end{array}$} & \multicolumn{2}{|c|}{$\begin{array}{l}\text { Samples completely consistent with expert } \\
\text { knowledge (round determination results to unit) }\end{array}$} & \multicolumn{2}{|c|}{$\begin{array}{l}\text { Harvesting time determination } \\
\text { (index be equal to or higher than 4) }\end{array}$} \\
\hline & & Raw & Corrected & Raw & Corrected & Raw & Conrected & Raw & Corrected \\
\hline 1 & 7 & 6.5 & 7.6 & 0.53 & 0.55 & 6 & 8 & \multirow{7}{*}{$\checkmark$} & $\checkmark$ \\
\hline 2 & 6 & 4.4 & 6.4 & 1.56 & 0.42 & 4 & 6 & & \multirow[t]{2}{*}{$\checkmark$} \\
\hline 3 & 6 & 1.4 & 3.3 & 4.59 & 2.70 & 1 & 3 & & \\
\hline 4 & 6 & 3.3 & 6.5 & 2.70 & 0.55 & 3 & 7 & & $\checkmark$ \\
\hline 5 & 5 & 3.3 & 6.5 & 1.69 & 1.47 & 3 & 6 & & $\checkmark$ \\
\hline 6 & 5 & 2.7 & 5.4 & 2.33 & 0.42 & 3 & 5 & & $\checkmark$ \\
\hline 7 & 7 & 3.3 & 6.5 & 3.70 & 0.50 & 3 & 6 & & $\checkmark$ \\
\hline 8 & 5 & 4.3 & 7.6 & 0.65 & 2.56 & 4 & 8 & \multirow{5}{*}{$\checkmark$} & $\checkmark$ \\
\hline 9 & 6 & 6.5 & 7.6 & 0.52 & 1.57 & 7 & 8 & & $\checkmark$ \\
\hline 10 & 6 & 2.5 & 5.6 & 3.50 & 0.42 & 2 & 6 & & $\checkmark$ \\
\hline 11 & 6 & 1.5 & 4.5 & 3.98 & 1.03 & 2 & 4 & & $\checkmark$ \\
\hline 12 & 7 & 1.4 & 4.5 & 5.60 & 2.50 & 1 & 4 & & $\checkmark$ \\
\hline & & & Average error & 2.6 & 1.2 & & & & \\
\hline
\end{tabular}

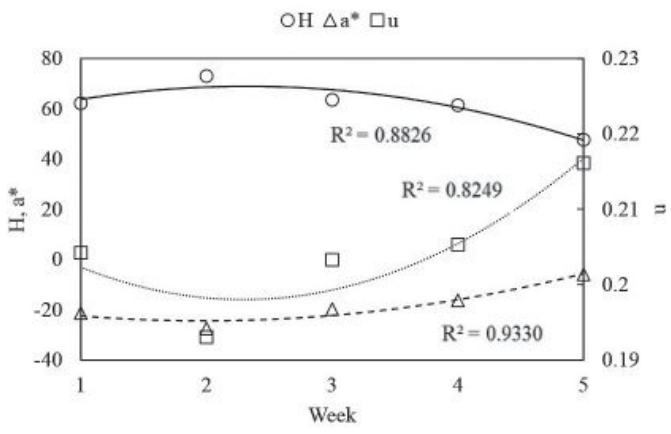

(a) Raw image.

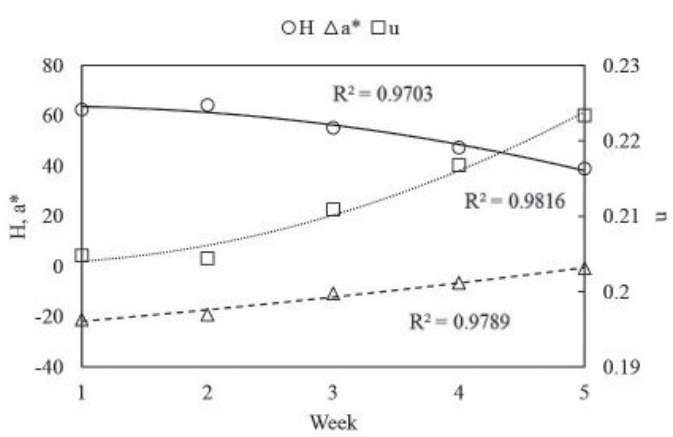

(b) Corrected image.

Figure 9 Result of surface color analysis.

\section{EXPERIMENT TO DETERMINE TIME TO HARVEST Apple}

An experiment to determine the time to harvest apples was carried out using the images of the apples taken outdoor. The proper harvest time for high-quality apples was determined by comparing the surface color and the ground color with the color chart. However, there were variations in the surface color depending on the angle of sunlight, because of which the ground color was determined with priority when it is harvested. Therefore, in this experiment, the determination was made using ground color.

The previous studies compared four kinds of determination methods (difference, shortest distance method, similarity method, linear function $)^{[7][8]}$. We used the shortest distance method that had then obtained best result.

In the shortest distance method, the values of $\mathrm{H}, \mathrm{a}^{*}$ and $\mathrm{u}$ were regarded as a $3 \mathrm{D}$ vector, the Euclidean distances of the ground color chart and the apple color were calculated. Specifically, we derived the color chart number for which the distance was shortest (first decision result), next shortest (second decision result), and calculated the decision result using real numbers based on the ratio of the two distances. The chart numbers corresponding to the harvesting season of Yataka are 4 and 5, where 6 or over represented over-ripe apple. However, in this study, a judgment of the harvesting time is number 4 or higher, including over-ripe apple.

Table 2 shows the results of the method using 3D Euclidean distance. Expert visual judgments in the table indicates the results of visual inspection by experts. In the raw image, the result did not agree with expert judgments in many samples. Further, even though all samples were actually suitable for harvesting, many were judged to be inappropriate (index less than 4). However, in the corrected image, the determination results generally agreed with expert judgments, and erroneous determinations were reduced compared to those prior to correction. Samples completely consistent with expert judgments were not found in the method using raw image, whereas three samples were confirmed in the method using corrected image.

From this, we conclude that the harvest period of apples can be judged more accurately using the method that employs $3 \mathrm{D}$ Euclidean distance. However, in the results in Table 2, there were cases where the judgment result by the proposed method was higher than the judgment result by experts. Considering that the judgment value is expressed by the value rounded off, the error value of 0.5 is considered to be within the allowable range. However, because there were samples exceeding the allowable range, we plan to verify by increasing the number of samples.

\section{CONCLUSION}

The purpose of this paper was to develop a method to quantitatively determine the proper time to harvest apples (Yataka). We first analyzed features useful for judging the time to harvest apples outdoors. We found that the H in HSV color space decreased with increase in the chart number, which is a breeding index, and the $u$ in $a^{*}$ and the $(u, v)$ chromaticity diagrams in the $L^{*} a^{*} b^{*}$ color space increased. We concluded that $\mathrm{H}, \mathrm{a}^{*}$, and $\mathrm{u}$ are useful in determining the proper harvest time of apples outdoors.

We then developed a method to reduce the influence of illumination changes outdoor, analyzed an outdoor color chart and apple color, and confirmed the usefulness of the proposed method. The analysis result of the color chart showed that the standard deviations of the values of $\mathrm{a}^{*}$ and $\mathrm{H}$ in the corrected image were 
lower than those in the raw image. The analysis of apple color expressed $\mathrm{a}^{*}$ and $\mathrm{H}$ along the state of growth in the corrected image. The $\mathrm{R}^{2}$ of the fitting curve showed the change in apple color value along with growth. This finding indicates that the effect of lighting conditions was reduced using the proposed method.

Finally, a harvesting time determination experiment was conducted using images taken outdoors. We confirmed that erroneous determination was reduced compared to the case before the correction by applying the proposed method. Hence, we believe that the proposed method is useful for determining the proper harvest time for apples outdoors. In future work, we plan to conduct similar experiments for other fruits. In the future work, we will increase the number of samples before and after harvest time and verify the usefulness of the proposed method.

Acknowledgement: The authors thank J. Ueta and Y. Sato, Akita Prefecture Fruit-tree Experiment Station, for useful discussions.

\section{References}

[1] Ministry of Agriculture, Forestry and Fisheries. Statistics on the agricultural labor force.

http://www.maff.go.jp/j/tokei/sihyo/data/08.html (Accessed 2016/12/16). (in Japanese)

[2] Yamamoto K.; Guo W.; Yoshioka Y.; Ninomiya S., "On plant detection of intact tomato fruits using image analysis and machine learning methods" Sensors, 14(7), 12191-12206 (2014).

[3] Sengupta S.; Lee WS., "Identification and determination of the number of immature green citrus fruit in a canopy under different ambient light conditions" Biosystems Engineering, 117, 51-61 (2014).
[4] Hayashi S.; Takeshita D.; Yamamoto S.; Saito S.; Saga K.; Imou K., "Collision-free control of a strawberry-harvesting robot by recognition of immature fruits" Journal of Society of High Technology in Agriculture, 25(1), 29-37 (2013). (in Japanese)

[5] 5. Hashimoto A.; Suehara K.; Kameoka T., "Quantitative evaluation of surface color of tomato fruits cultivated in remote farm using digital camera images" SICE Journal of Control, Measurement, and System Integration, 5(1), 18-23 (2012).

[6] Kishi T.; Kato K.; Mori N.; Sato E.; Doi R.; Mizoguchi M., "Determination of criteria for apple harvesting stage using simple monitoring system" Annual Meeting of The Japanese Society of Irrigation, Drainage and Rural Engineering, 792793 (2010). (in Japanese)

[7] Ishii M.; Kusada I.; Yamane H., "Quantitative decision method of appropriate apple harvest time using color information" IEEJ Transactions on Electronics, Information and Systems, 137(9), 1209-1218 (2017). (in Japanese)

[8] Ishii M,; Kusada I,; Yamane H., "Image correction method to determine appropriate apple harvest time for outdoor trees" Journal of Institute of Industrial Applications Engineers (JIIAE), 5(1), 1-6 (2017).

[9] Takagi. M; Shimoda H., "Handbook of image analysis [Revised Edition]" University of Tokyo Press (2004). (in Japanese)

[10] Uchikawa K., "Handbook of visual information processing" Vision Society of Japan, Asakura Publishing Co., Ltd. (2000). (in Japanese)

[11] Forsyth. D.A.; Ponce J., "Computer vision: A method approach" Kyoritsu Shuppan Co., Ltd. (2007) (in Japanese) 